\title{
Correlation Cost - Performance in Terms of Management Accounting
}

\author{
Dumitru Ene, University of Wallachia, Targoviste, Romania
}

\begin{abstract}
Management accounting system is a useful tool for enterprise management, which aims to achieve performance piloting enterprise by promoting efficiency and effectiveness. To be successful in today's economic environment requires the use of a calculations system and management costs. Purpose of calculating costs is to identify cases not only transfer the cost objects. This approach shows the ability of the system for calculating the cost of providing an analysis linking financial performance of business processes and activities cost sale. The firms use type information in various forms in making decisions. The manager expects the management accounting a permanent assistance before, during and after the action, to define objectives, to understand whether the objectives are relevant and to measure performance.
\end{abstract}

\section{Keywords}

Management accounting, cost, value, performance, costing system, financial performance, overall performance, efficiency, effectiveness, the object cost;

JEL Code: $M 41$

\section{Current Issues in Theory and Managerial Accounting Method}

Current Issue able to challenge managerial accounting theory and method relate to: a reassessment of the concept and identify key performance indicators characterizing the performance: the concept of 'cost-value", target cost and cost of activities . Analyzed in terms of domain information and a business decision, and shall cause accounts, assist and decide on the company's financial position, economic and financial performance and cash flows arising from investing / finance, employment / resource use, production / distribution of wealth created by an entity that is simultaneously legal, economic and financial. To be efficient in the current economic environment requires the use of a calculations system and management costs. Cost calculation goal is to identify the causes not just transfer the cost objects .

This approach shows the ability of system for calculating the cost of providing an analysis linking financial performance of business processes and activities. French National Accounting Council defined the management accounting since 1996, that is designed primarily business needs, it is a part of its information system, providing an economic modeling company in order to meet the objectives of performance measurement and aid in decision making. Of its composition are:

- Performance measurement process

- Substantiation methods of decision .

\section{Chronological Stages of the Process of Performance Measurement}

International Federation of Accountants (IFAC), in "Managerial Accounting Concepts", published in February 1989 and revised in 1998, admits that there are different names in the 
world of these records, costs for knowledge, decisions and performance evaluation firm grounding. Are important but the development and qualitative change in time, management accounting, this conceptual framework developed by IFAC, which can be analyzed chronologically into four distinct phases.

In the four distinct stages mentioned specific items appear to measure process performance:

- Round that one, before 1950, the emphasis is on determining the costs and their control, the use of budgetary techniques and cost accounting;

- Stage-II, until 1965, when the emphasis shifted to providing information for planning and management control, the responsibility for providing accounting information and careful analysis of decisions taken on them;

- Stage-III, until 1985, when attention was focused on reducing loss of resources used in business processes, using techniques of process analysis and cost management;

- Stage-IV, until 1995, when attention shifted to creating value efficiently using resources, using advanced techniques to examine the requirements for creating value, in terms of customer (consumer) ownership, but also to assess the organizational innovation.

The current stage of development, managerial accounting (management), shows the International Federation of Accountants, in its preface conceptual framework, the needs of firms operating in a dynamic environment, competition and competitive.

Two of the concepts that dominate the modern management of organizations are value and performance. We observe (in Romania) this is the statement (in internal or external environment of business) of such value creation for customer and shareholder or achieve global performance claims. These may be just nice words or, conversely, may be a synthesis of the general approach to company management. We can use cost as inducer of value and, depending on the characteristics of competition and how to use the product, cost is considered insufficient for assessing performance, it must be supplemented by using a tool to express the request. Recitals above are all many reasons that handle the company must adapt to new conditions that characterize the context in which the undertaking. Up to now several decades, productivity growth and cost reduction strategy was a satisfactory and easily implemented organisation. Today economic context is another and firm performance is subject to several competitive advantages factors. These is to be declined by the structure so as to be able to act on them and then be able to measure acquired progress .In addition, management tools are closely related to strategy, but also the structure (cut) ${ }^{1}$ organization. Structure becomes a key performance parameter and a variable to be managed, a lever action for flexibility. The new management is to compel a company built to work across vertical ${ }^{2}$.

Cost is still an inducer of value, but not sufficient for performance evaluation, so depending on the characteristics of competition and how to use the product, use the cost must be supplemented with a tool to express themselves more on request. To rely on the rarity value, management accounting must take into account certain factors such as quality, flexibility and time, which does not deal with traditionally management accounting, but which have become strategic stakes. Type companies use cost information in various forms in making decisions. The manager expected of a management accounting permanently assistance before, during and after the action, in order to define objectives, to understand whether the objectives are relevant and to measure performance. Cost calculation goal is to identify causes and not just their transfer to the cost objects. This approach shows the ability of computing the cost of providing an analysis linking financial performance of business processes and activities..

\section{Costs Control and Performance Measurement Activities}

Enterprise management involves measuring costs and performance and their management . For performance measurement is calculated projected costs (standard or exanthema) and compared with realized costs (real or expost). The conditions that characterize the current global economic environment, the most important objective of an accounting system costing 
seems to be able to estimate involved total product offering. Calculating the full cost stakes are high: performance assessment at the centers of responsibility, highlighting the effect of "chain cuts" in the case of processes and activities, assess the financial accounting, decision making on products, customers and activities.

A modern management characterized by the fact that performance and accountability that are global, collective, and costs must be integrated within the concept of value, involves the use of computer systems and performance measurement.

Standard cost method has its genesis in SUA where appeared in 1901 under the name "Estimated cost system"(The pre-calculated cost), promoting first cost is determined before construction start. Standard cost has an pre-calculated cost to assess the performance over a certain period of time. Trough „Estimated cost system "was transformed in 1918 in „, Standard cost accounting" (Standard cost calculation).

Performance on a charge there are two conceptual approaches: performance is a measure ability to achieve a goal set a standard by determining the relationship: the real cost - the standard cost. Given the favorable or unfavorable context, performance is measured by comparing the deviation cost $\%$ activity $\%$ deviation.

Deviation of activity $=($ actual-activity standard deviation $) \times 100 /$ standard activity.

$\mathrm{ABC}$ method considers that a firm is competitive when producing value for its customers, consuming minimal resources. The Cost-value tandem is an axle for restructuring the management priority, highlighting the activities that contribute to product development, namely those that affect its characteristics, the customer is ready to pay. The "nonproductive" nature attribute an activity that does not relate directly to the final product is still present in the assessment activities of factory. Because this case, accounting ignores some activities ( so called "'support"), but which are vectors of performance.

Method of target costing, target costing aims to reduce costs while taking into account market strategy, production management, human resources management and media relations întrepinderii.Raportat value engineering "Target-Costing" as a unitary concept and closed the management cost through functional analysis is oriented to the report, "value-cost-proceeds cost".

New vision for cross ABM's specific processes leads to redefining the concept of performance and yours assessment. The new vision or performance is a multi-vision, which includes issues of cost, terms, benefits and quality of participation in value creation and measurement is considering eliminating its effects on new indicators. The new performance indicators are classified into three categories:

-indicators to measure performance;

-indicators of management performance;

-indicators tracking action plans and progress.

Measure performance indicators assess the result of activities or processes being addressed in existing information systems, integrated in a multi-vision: the unit cost of an inducer, the average waiting time, customer satisfaction rate, etc..

Management performance indicators are defined by means of quality management tools aimed at detecting the causes of failure. Indicators for tracking progress brings together all the indicators that allow advance action plan, was recovered in architecture scoreboards and reporting system of enterprise.

Optimizing performance translates to optimize life cycle that becomes a gestiune.Costul not obtained additive, but as a "measure of value", which is what the customer is willing to pay for product. The factory not manage to reduce the cost but optimizing the cost-value.

Cost-volume-procedees - model is a profit that studies relations existing between several factors: the price of products, volume or activity levels, unit variable cost, total fixed costs, production structure. The enterprise can change the values of these variables in order to obtain desirable objective. The rely indicators of the model are: margin on variable costs, the margin rate on variable costs, lever operational cost structure. 
Companies must not manage to reduce cost, but cost-value. The solution to optimize the cost-value is method of calculation directly - costing. Efforts a specialists to find a system calculation, which to ensure: first determine the operational unit cost of production, and on the other hand can easily determine indicators essential grounding for management decisions in the short term resulted calculation directly - directly costing. The directly-costing calculation, the indicators that determines, allow management to make decisions to optimize outcome of operation and may provide follow such decisions.

There is a correlation between: strategy-performance-management control? I consider that performance measurement is an attribute of management control can not be addressed outside the objectives outlined for each organization. In this issue is clarified two points:

-Mission - for which there is a business?

-Vision-to which the business is heading?

Performance is assessed in connection with strategically objectives. The typology of strategies to address the resulting diversity of afacerii.Henry Mintzberg relizat two groups of strategies in his strategy: towards a general framework (Generic Srategies: Tpward Comprehensive Framework). The first one divides strategies in static and dynamically. The static strategies is a conservative approach to maintain current market position by focusing on qualitative aspects. The dynamically strategies promote fast or major changes at the enterprise level or at the level of significant activities. The second approach typological has in center development size business and delimit such strategies: penetration - starts from existing products and markets and proposes new actions to capture new markets, market development - promoting new products on the market or reduce the number market segments but increases the size of their product development - increases the amount of products by increasing the use of existing capacity or increase manufacturing lines, the diversification aims to expand the range of products in the same field of work or related fields .

Vision gives general signs (strategy) of walking an organization and is based on flexibility. The mission describes the basic functions of the organization in terms of goods and services produced and provided to customers (Mintzberg).

Mission and planning are two elements in the connection, the mission has an important role in planning. The organizations can be considered machinery of growth, growth that can be measured differently by : revenues, profitability, return on investment, market share, number of staff, number of products, cash, etc..

A performance measurement system will show the degree to which objectives were achieved entity. Performance measurement is related to: spaces of responsibility, size of organization and authority vested in managers without which no motivation.. In this context, performance measurement should be determined by the type of structure an organization to be evaluated. Such structures may occur as cost centers, revenue, profits, investment.

Performance requires a comprehensive vision of internal and external parameters, quantitative and qualitative, technical and human, physical and financial. Overall performance assessment integrating multiple levels: for production, for sale, for finance . Consistency management indicators retained in each profit center and each operational center and consistent with defined indicators at enterprise level are essential. The center would charge indicators are not always running to be chosen to complete the analysis of its management. There are many cases in which indicators should be changed to optimize overall management . Optimizing each subset of the enterprise does not necessarily lead to optimization company, nor to optimize the implementation strategy . Choosing appropriate indicators is one of the fundamental responsibilities of management control.

What are the main instruments for measuring and managing performance ? Modern management organizations operate with two concepts: the value and performance. To assess performance, to be managed value . But value is not measurable and should therefore be reconsidered processes involved in its creation that have a global vision of the interdependence of external and internal parameters, quantitative and qualitative, technical and human resources, management of physical and financial of management. Performance is 
not purely financial and indicators used to date (firm size, profitability and revenue, treasury) condemns the company to position reactive not proactive. The reality is that neither can progress continuously on financial their. Financial scandals of recent years have highlighted the limits of financial information to capture all facets of performance. Performance is ambiguous and integrator concept assuming equilibrium and causal relationship between internal and external factors of the organization. Why not just performance tracked and measured, but must be managed, "We can not thank just count all the fruits of of a tree count. Must all contribute to creating a fertile soil and are concerned long-term health of the tree $^{\prime \prime 3}$. In the current environment, management control should be to enrich content to allow steering of performance and managing change.

Organization as complex system, adaptive, with a specific purpose and open to the environment, can be considered as a set of subsystems . In light of management, the company includes subsystem leader (decision), led subsystem (operational) and information subsystem that provides the connection between the first two. Purpose system that involves business objectives set by strategy requires a system analysis and performance measurement in decision-making system. Building such a system performance analysis should address mainly the following problems: establishing organizational subdivisions must receive information about the performance achieved, specifying the decision centers, and ways of presenting information on activities conducted, coordination organizational subdivisions receiving information about the performance achieved operational subsystem.

Solve these problems, identify relationships between subsystems, components, highlighting the relevant information to enable decision-operational subsystem and subsystem to achieve the objectives can be fostered by use of statements of performance monitoring and reporting: the dashboard, reporting, Balance

\section{Bibliography}

1.Albu, N., Albu, C. (2003), Performance management tools, Vol.I and II, Economical Publishing House, Bucharest

2.Serieyx, H. (1999), Le zero mépris, Dunod, Paris

3. www.ub.ro

4. www.infoeuropa.ro 